\section{Mission Accomplished}

\author{
Geon Ho Bahn \\ Editor-in-Chief, Korean Academy of Child and Adolescent Psychiatry
}

\title{
임무 완수
}

반 건 호

대한소아청소년정신의학회 편집위원장

대한소아청소년정신의학회는 주의력결핍 과잉행동장애 (ADHD) 치료권고안을 본 학술지 2007년 18권 1호에 게재한 바 있습니다. 당시 건강보험심사평가원에서 atomoxetine 사용 이나 성인의 약물치료를 인정하지 않았습니다. 이후 2013년 DSM-5 발표, 2016년 9월 성인 ADHD 의료보험 적용 등의 변 화에 발맞춰 학회 주도로 치료권고안 개정판을 이번 호에 게 재합니다. 개정안 집필에서 강조한 부분은, 1) 소아기는 물론 청소년 및 성인 $\mathrm{ADHD}$ 에 대한 연구결과, 2) 공존질환이 동반 된 ADHD 치료법, 3) 비약물적 치료의 국내 자료 등입니다. 이 에 따라 개정된 내용은 2007년 권고안의 약 두 배 분량이며, 이전 권고안처럼 4부로 구성하였습니다. 김은진 등이 '서론, 임 상증상 및 공존질환, 이문수 등이 '진단 및 평가', 김효원 등이 ‘약물치료', 신윤미 등이 '비약물적 치료'를 저술하였습니다.

이번 호의 원저로는 선우현정 등이 '자폐스펙트럼장애의 조 기선별에 대한 관련 분야 종사자의 인식 조사를 통해 일선 업 무 담당자들이 생각하는 자폐스펙트럼장애의 일차 선별에 필 요한 도구에 포함되어야 하는 증상과 징후를 조사하였습니 다. 신민섭 등이 참여한 스마트 토이를 활용한 아동용 인지 능력 증진 프로그램의 예비 효과 연구'는 인공지능 시대에 걸 맞게 로봇을 이용하여 기억력 증진을 시도한 예비연구입니다. $\mathrm{ADHD}$ 아동에게 비약물적 중재 기법인 코그메드 작업기억력 훈련을 적용한 뒤 효과를 평정한 두 개의 논문을 소개합니다. 이은경 등은 '약물치료 중인 주의력결핍 과잉행동장애 아동 청소년에서 작업기억훈련이 행동문제와 부모 스트레스에 미 치는 부가적 효과', 김혜선 등은 '약물치료 중인 주의력결핍 과 잉행동장애 아동 청소년에서 작업기억력 훈련이 임상증상과

This is an Open Access article distributed under the terms of the Creative Commons Attribution Non-Commercial License (http://creativecommons.org/licenses/by-nc/4.0) which permits unrestricted non-commercial use, distribution, and reproduction in any medium, provided the original work is properly cited.
신경심리소견에 미치는 부가적 효과를 발표합니다. 최성구 등 은 ‘일병원에서 진단된 극조기발병조현병 환자의 인구학적 특 성, 약물치료 양상 및 치료결과'를 통해 13세 미만 인구에서 발병한 조현병 환자 69명의 임상특성을 정리하였습니다. 이서 윤 등은 ‘조산아의 저출생체중과 연령이 학령전기 인지수행에 미치는 영향'에서 $1500 \mathrm{~g}$ 미만인 극소저출생체중아, $1000 \mathrm{~g}$ 미 만인 초극소저출생체중아의 성장과정에서 인지능력이 어떠 한 발달을 하는지 확인하였습니다. 김성완 등은 ‘학술지 소아 청소년정신의학의 공저 네트워크 분석'에서 우리 학회지에 게 재된 논문과 그 저자들에 대해 분석하였습니다. 최근 십 년간 발간된 본 학회지의 원고 251 편의 저자 546 명을 분석한 결과, 상위 $20 \%$ 의 저자가 나머지 $80 \%$ 의 저자를 이끌어 가고 있다 고 해석하였습니다.

우리 학회지는 올해 28년 차이고 미국 소아청소년정신의학 회의 공식학술지인 소위 '오렌지저널'은 딱 두 배인 56년 차입 니다. 오렌지저널의 편집장 임기는 5 년이고 매번 중임합니다. 그래서 56년의 역사에 2017년 현재 편집장을 포함하여 모두 6 명의 편집장이 있었습니다. 1997 2007년은 Mina Dulcan이 었고, 2008 2018년은 Andrès Martin입니다. 차기 편집장은 Douglas Novin이며, 2017년 한 해는 현재 편집장과 차기 편 집장이 같이 편집 업무를 수행합니다. 2008년 오렌지저널의 Impact Factor는 4.845였고, 2015년에는 7.182로 껑충 뛰었습 니다. 오늘 새벽 편집인의 글을 마무리하는 동안 우리 대통령 이 구치소로 가는 모습을 보면서 문득 우리는 역사에서 무엇 을 배울 것인가 하는 생각이 들었습니다. 우리 학회지의 장점은 무엇이고, 오렌지저널에서 배울 것은 무엇인지? 아직은 3개월 마다 간신히 편집 마감하는 수준이지만, 언젠가 다음 편집이 사에게 넘길 때 “임무 완수”라고 신나게 외치리라 기대합니다. 